\title{
Physicochemical Studies on Thienyl Chalcone Derivative for Nonlinear Optical Application
}

\author{
A. N. Prabhu, ${ }^{1}$ A. Jayarama, ${ }^{2}$ K. Subrahmanya Bhat, ${ }^{3}$ \\ K. B. Manjunatha, ${ }^{4}$ G. Umesh, ${ }^{4}$ and V. Upadhyaya ${ }^{1}$ \\ ${ }^{1}$ Department of Physics, Manipal Institute of Technology, Manipal University, Manipal 576104, India \\ ${ }^{2}$ Department of Physics, Mangalore Institute of Technology \& Engineering (MITE), Moodabidri 574225, India \\ ${ }^{3}$ Department of Chemistry, Manipal Institute of Technology, Manipal University, Manipal 576104, India \\ ${ }^{4}$ Department of Physics, NMAM Institute of Technology, Nitte 574110, India
}

Correspondence should be addressed to A. Jayarama; jrmarasalike@yahoo.co.in

Received 25 August 2013; Accepted 8 October 2013

Academic Editors: J. Luo and H. S. Yathirajan

Copyright (C) 2013 A. N. Prabhu et al. This is an open access article distributed under the Creative Commons Attribution License, which permits unrestricted use, distribution, and reproduction in any medium, provided the original work is properly cited.

\begin{abstract}
Single crystals of 1-(5-chlorothiophen-2-yl)-3-(2,4,5-trimethoxyphenyl)prop-2-en-1-one (CTTMP) having nonlinear optical property have been grown by slow evaporation technique. The functional groups were identified by FT-IR and NMR techniques. The mechanical property of the crystals was studied using Vicker's microhardness tester and the load dependence hardness was observed. The material is dimensionally stable up to $112^{\circ} \mathrm{C}$. The dielectric properties of the crystals were determined using semiconductor characterization system. The optical limiting behavior of the crystal was studied using Z-scan technique.
\end{abstract}

\section{Introduction}

Nonlinear optical (NLO) materials play an important role in fields like photonics and optoelectronics [1]. Such materials find application in technologies such as optical computing and optical communication $[2,3]$. Recently, much focus has been given to organic NLO materials for applications in field of photonics [4] due to their large nonlinear response, good optical limiting behavior, fast switching time, and convenient optimization routes through molecular design compared to the currently used inorganic materials [5]. Chalcone derivatives are one of the interesting groups of materials as they are exhibiting high NLO coefficients and good crystallizability [6]. The intramolecular charge-transfer feature available in the chalcone allows us to design new molecules substituted for donor or acceptor groups, which gives an understanding of structure-property relationship [7]. Several chalcone compounds are reported to crystallize in noncentrosymmetric crystal pattern and provide necessary configuration for NLO activity with two planar benzene rings connected through a conjugated double bond and a carbonyl moiety $[8,9]$. Most of the work reported on these chalcones is on second order nonlinear efficiency $[10,11]$. The strong delocalization of $\pi$ electrons in these systems is responsible for high molecular polarizability and their remarkable third order nonlinearities. However the third order nonlinear efficiency of Donor- $\pi$-Acceptor- $\pi$-Donor $(D-\pi-A-\pi-D)$ type of molecules with centrosymmetric crystal structure is not found in the literature. Recently, we have reported crystal structures and second or third order nonlinear optical properties of few chalcone derivatives having thienyl group [12, 13]. We have also reported synthesis and crystal structure of 1-(5-chlorothiophen-2-yl)-3-(2,4,5-trimethoxyphenyl) prop2 -en-1-one derivative [14]. However, physicochemical property of this derivative has not been investigated. In order to find the feasibility of CTTMP crystal for photonic device applications the optical limiting behavior and mechanical and thermal stability have been studied.

\section{Experimental Procedure}

2.1. Synthesis, Solubility, Crystal Growth, and Morphology. The compound CTTMP was synthesized by using the general 


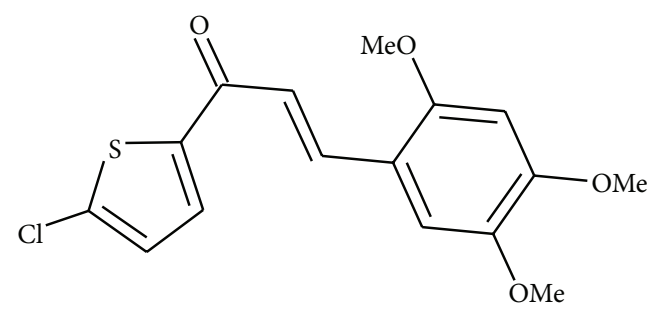

FIGURE 1: Chemical structure of CTTMP.

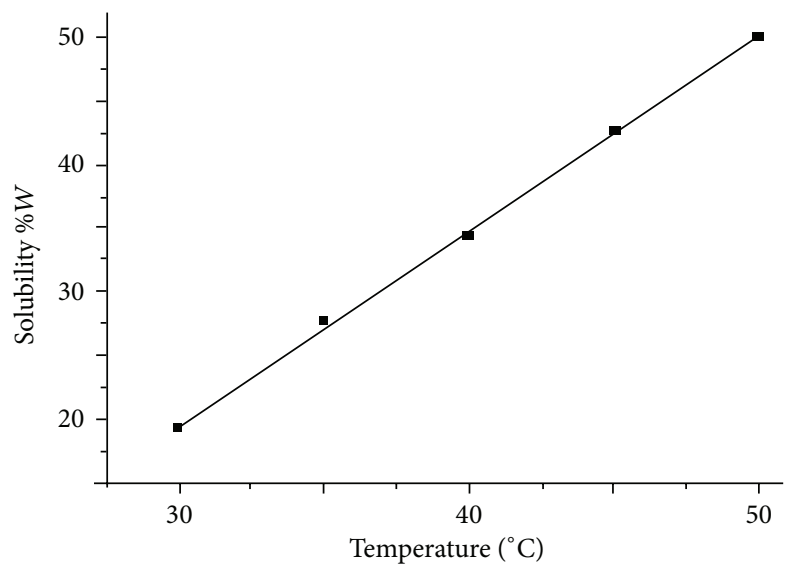

FIGURE 2: Solubility of CTTMP in DMF.

procedure reported in the literature [14]. The chemical structure of the compound is given in Figure 1.

The solubility studies in organic solvents showed the compound is sparingly soluble in ethanol, methanol, DMF, and acetone. To grow large single crystals of CTTMP, we preferred DMF due to its moderate solubility and less volatile nature of the solvent. A known volume of solvent was taken in a conical flask, which was immersed in a constant temperature bath. The powdered sample was added until the dissolution ceased. The solubility of CTTMP at various temperatures, from room temperature to $50^{\circ} \mathrm{C}$, was determined and is shown in Figure 2. The solubility increases almost linearly with the temperature and hence slow cooling or slow evaporation at constant temperature could be a method of choice to grow the single crystals of CTTMP.

Saturated solution of CTTMP in dimethyl formamide (DMF) was prepared at $30^{\circ} \mathrm{C}$ and was filtered to remove the suspended particles, if any and kept undisturbed in a dustfree environment. At the period of super saturation, tiny crystals were nucleated. They were allowed to grow to a period of two to three days and then harvested. The laboratory grown crystals of CTTMP are shown in Figure 3. The morphology of the CTTMP single crystal was indexed using the single crystal $\mathrm{X}$-ray diffraction data reported [15] in the literature as input to the morphology indexing computer program (WinXMorph) [16]. The indexed morphology of CTTMP is shown in Figure 4 . The crystals are prismatic, with large habit face (1 $\left.\begin{array}{ll}0 & 0\end{array}\right)$ and distinct cleavage plane $\left(\begin{array}{ll}0 & 1\end{array}\right)$. It is clear that the (1 0 0 ) plane is having larger area due to the reduced growth rate

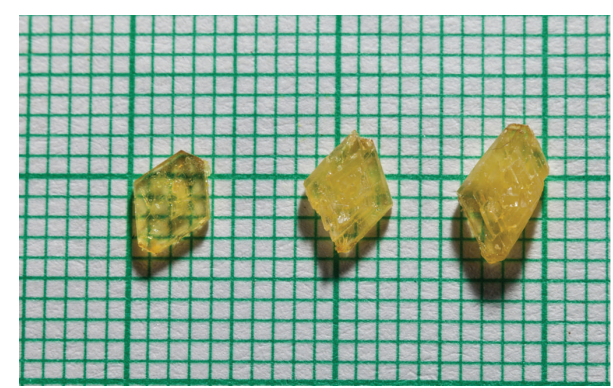

FIgURE 3: Single crystals of CTTMP grown using DMF.

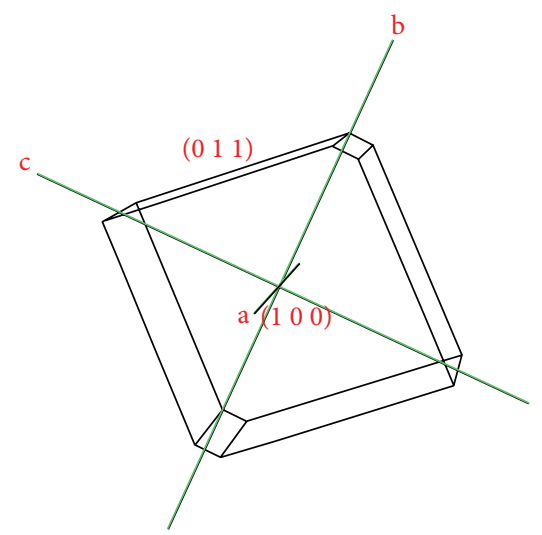

FIGURE 4: Indexed morphology of CTTMP.

along the crystallographic a-direction compared to b- and cdirections.

\section{Result and Discussion}

3.1. FT-IR and NMR Spectral Studies. The FT-IR spectrum of the synthesized material was recorded in the wave number range $400-4000 \mathrm{~cm}^{-1}$ by $\mathrm{KBr}$ pellet technique (SHIMADZU 8400S FT-IR spectrometer). The spectrum shows the characteristic absorption at $1647 \mathrm{~cm}^{-1}$ attributable to $\mathrm{C}=\mathrm{O}$ group of $\alpha, \beta$ - unsaturated carbonyl compound confirming the formation of 1-(5-chlorothiophen-2-yl)-3-(2,4,5trimethoxyphenyl) prop-2-en-1-one.

Further, the compound is also characterized using proton NMR. Thus, the two doublets observed at $\delta 8.022$ and 7.212 with a coupling constant of 15.2 correspond to protons of$\mathrm{CH}=\mathrm{CH}$-group. Other characteristic peaks observed in the spectrum are $\delta: 7.543$ (d, $1 \mathrm{H}, \mathrm{H}$ of thiophene ring), 7.008 (d, $1 \mathrm{H}, \mathrm{H}$ of thiophene ring), $6.914(\mathrm{t}, 1 \mathrm{H}, \mathrm{H}$ of aromatic ring), 6.444 (d, $2 \mathrm{H}, \mathrm{H}$ of aromatic ring), and 3.849 (3 closely packed singlet, $\left.9 \mathrm{H}, 3 \times \mathrm{OCH}_{3}\right)$.

3.2. Surface Structure of the Crystals. The most common habit of the crystal CTTMP grown in DMF is prismatic. The scanning electron micrograph analysis was carried out to visualize growth patterns of single crystals by using the instrument JEOL JSM-6380LA. The SEM of the crystal (Figure 5) shows step-like patterns on the surface, which confirms the layered growth of the crystal. 


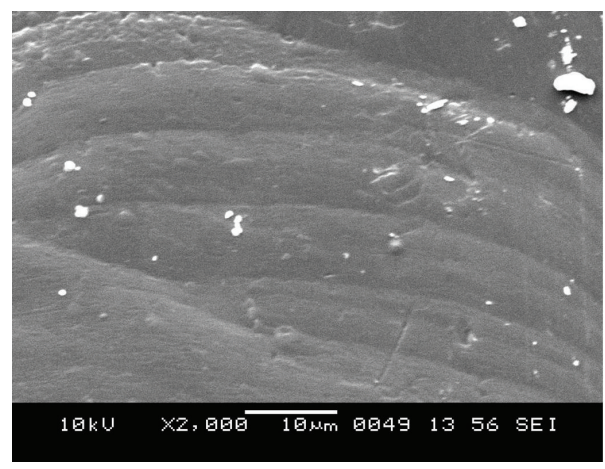

FIGURE 5: SEM image of CTTMP.

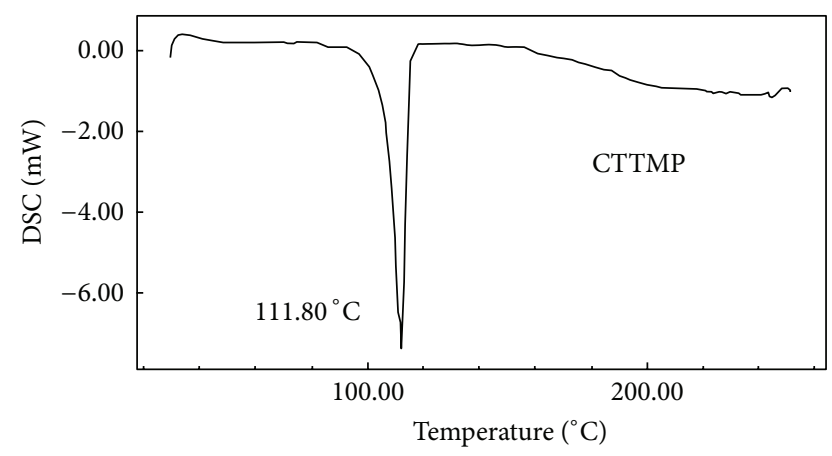

FiguRE 6: DSC curve of CTTMP.

3.3. Thermal and Mechanical Stability. The thermal property of 1-(5-chlorothiophen-2-yl)-3-(2,4,5-trimethoxyphenyl)prop-2-en-1-one was studied in the powder form by recording the differential scanning calorimetry (DSC) response curve in the temperature range from $30^{\circ} \mathrm{C}$ to $250^{\circ} \mathrm{C}$, at a rate of $10^{\circ} \mathrm{C} / \mathrm{min}$, in nitrogen atmosphere using SHIMADZU differential scanning calorimetry (DSC-60). The DSC plot given in Figure 6 shows a sharp endothermic peak at $112^{\circ} \mathrm{C}$, which corresponds to the melting point of CTTMP.

The melting point of the crystals infers that the material may be suitable for device fabrication up to a temperature of $112^{\circ} \mathrm{C}$. Further it indicates that there is no phase transition before melting. The sharpness of the peak shows the good degree of crystallinity and purity of the sample. Density of the compound was measured using specific gravity bottle at ambient temperature $\left(27^{\circ} \mathrm{C}\right)$. The average value of density was found to be $1.356 \mathrm{~g} / \mathrm{cm}^{3}$.

The hardness of the crystal is an important factor to be considered in device fabrication. The hardness of the crystal was found from Vicker's microhardness tester. Smooth and flat surfaces of the crystals were selected for this study and for each trial indentation time were $10 \mathrm{~s}$ and the diagonal lengths of the indented impression were measured for different loads. Vicker's microhardness number was calculated using the relation $\mathrm{VHN}=1.8544 \mathrm{P} / \mathrm{d}^{2} \mathrm{~kg} \cdot \mathrm{mm}^{-2}$, where $\mathrm{d}$ is the mean diagonal length of the indenter impression in millimeter and $\mathrm{P}$ is the applied load in $\mathrm{kg}$. The load dependence of Vicker's hardness number is shown in Figure 7. Vicker's hardness

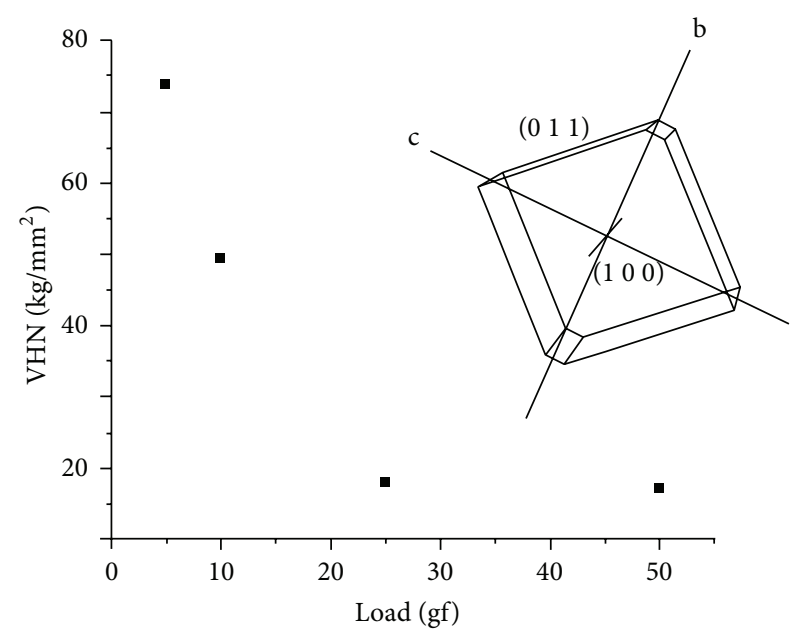

FIGURE 7: Load dependence of Vicker's hardness of CTTMP crystal.

number initially decreased with increase in load and saturated above the load of $50 \mathrm{~g}$. The decrease in VHN value with load may be due to the plastic flow of the material. The measurement performed beyond a load of $25 \mathrm{~g}$ resulted in severe cracks. This is due to the release of internal stress generated locally by indentation. Similar load dependence was observed in other NLO crystals such as 3-(3,4-dimethoxyphenyl)-1-(4methoxyphenyl) prop-2-en-1-one [17], urea, and N-methyl urea [18].

3.4. Linear and Nonlinear Optical Studies. The refractive index of the CTTMP single crystal was determined by Brewster's angle method. It was found to be 1.582 at $632.8 \mathrm{~nm}$ and 1.594 at $543.5 \mathrm{~nm}$, respectively. The refractive indices were measured only along one of the crystallographic directions due to its platy type growth. By the measurement of refractive index it is possible to measure the electrooptic r-coefficients. Electrooptic effect is useful in the modulation of light intensity. Since CTTMP has higher value of index of refraction at $632.8 \mathrm{~nm}$ and $543.5 \mathrm{~nm}$, it can be used to modulate light intensity in optical limiters.

The SHG conversion efficiency of the compound was measured by powder technique [19] using Nd:YAG laser of wavelength $1064 \mathrm{~nm}$ and beam energy was $4 \mathrm{~mJ} /$ pulse. The compound did not show SHG efficiency may be attributed to the fact that it crystallizes with inversion symmetry as revealed from single crystal X-ray diffraction study reported by us earlier [15].

Prabhu et al. [14] reported third order optical nonlinearities of CTTMP sample using single beam Z-scan technique. The third order NLO property of CTTMP is found to be higher than that of CTDMP compound [12]. From the reported studies it has been observed that the compound exhibits two-photon absorption as well as self-defocusing effect $[20,21]$. The optical limiting behavior of CTTMP is extracted from the open aperture Z-scan curve shown in Figure 8 . The samples behave linearly until incident fluence of $10^{4} \mathrm{~J} / \mathrm{m}^{2}$ and transmittance decreases for higher incident fluencies, suggesting the occurrence of optical limiting. 


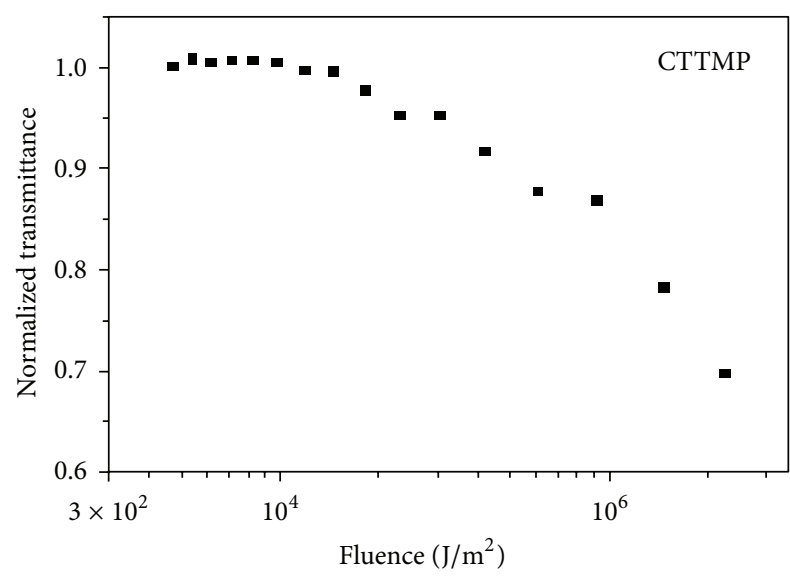

FIgURE 8: Optical limiting behavior of CTTMP.

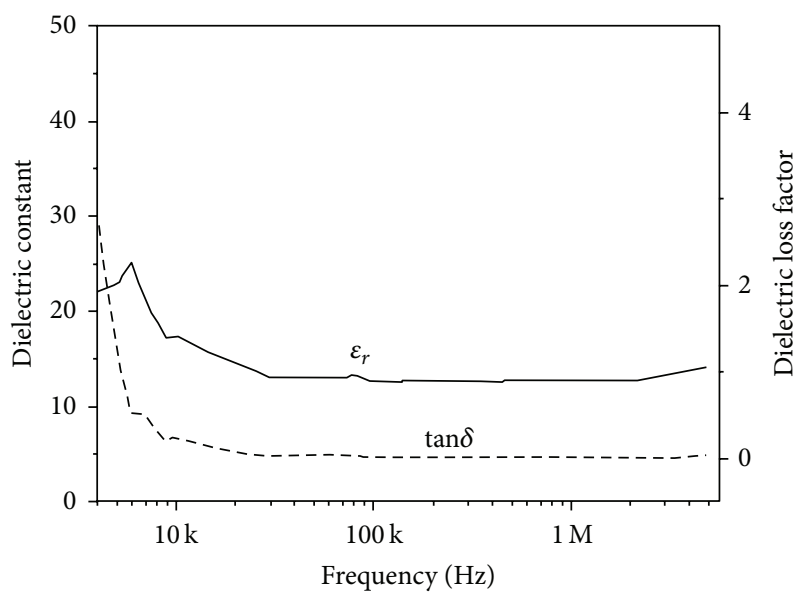

FIGURE 9: Dielectric constant and dielectric loss factor of CTTMP.

The limiting threshold of the sample at the concentration of $1 \times 10^{-3} \mathrm{~mol} / \mathrm{L}$ is $7 \times 10^{4} \mathrm{~J} / \mathrm{m}^{2}$.

3.5. Dielectric Properties of the Crystals. The dielectric studies were carried out using semiconductor characterization system (Kethely 4200SCS) for frequencies ranging from $1 \mathrm{kHz}$ to $5 \mathrm{MHz}$ with an applied voltage $1 \mathrm{mV}$ at laboratory temperature. The graph of the dielectric constant $\varepsilon_{r}$ (solid line) and the dielectric loss factor $\tan \delta$ (dashed line) at various frequencies for the crystal plate of CTTMP is shown in Figure 9. The graph shows that $\varepsilon_{r}$ and $\tan \delta$ values were not varying much with higher frequencies. Also the dielectric loss factor is very low, except at low frequencies. The slightly higher values of $\varepsilon_{r}$ and $\tan \delta$ at low frequencies may be due to factors like grain boundaries and defects. The dielectric constant of CTTMP crystal is comparable to those of wellestablished NLO crystals such as $\mathrm{OH} 1$ and DAST as molecular structures of CTTMP are quite comparable with an extended conjugation.

3.6. Structure-NLO Property Relationship. CTTMP is having high third order nonlinearity due to the delocalization of $\pi$ electrons. The molecular structure of the compound contains chlorine at 5-position of thiophene ring which can act as an electron donating group by mesomeric effect. The $\mathrm{OCH}_{3}$ group is also a donor group. The electron donating strength of the $\mathrm{OCH}_{3}$ is greater than $\mathrm{Cl}$. The CTTMP molecule containing $\mathrm{Cl}$ and three $\mathrm{OCH}_{3}$ groups at the ends and an electron acceptor carbonyl $(\mathrm{C}=\mathrm{O})$ group at the middle forms a donor- $\pi$-acceptor- $\pi$-donor (D- $\pi$-A- $\pi$-D) system, where charge transfer takes place from the donor end to the acceptor at the middle of the molecule. The charge transfer to the carbonyl group is more effective from the donor attached to the phenyl group, rather than the thiophene group (asymmetric charge transfer), leading to large third order optical nonlinearity. Due to steric hindrance, the substitution of two $\mathrm{OCH}_{3}$ groups at the second and third positions of the phenyl ring reduces the third order optical nonlinearity [12], whereas substitution of three $\mathrm{OCH}_{3}$ groups in the phenyl moiety enhances the third order nonlinearity.

\section{Conclusion}

CTTMP single crystals were grown by slow evaporation solution growth technique using DMF as the solvent. Scanning electron microscope confirms step-like growth of the crystals. The mechanical and thermal stability of the material shows it as a promising material for NLO applications. Third order NLO studies indicate the molecule exhibits twophoton absorption, good optical limiting behavior, and selfdefocusing effect. Dielectric studies indicate that the values of $\varepsilon_{r}$ and $\tan \delta$ are found to be stable at higher frequencies. Substitution of three $\mathrm{OCH}_{3}$ groups in the phenyl moiety enhances the third order nonlinearity, because of the net charge transfer, and hence the dipole moment increases.

\section{Conflict of Interests}

The authors declare that there is no conflict of interests.

\section{Acknowledgments}

The authors thank M. Srinivasulu and Ajith Kumar, Department of Chemistry, Manipal Institute of Technology, Manipal University, India, for their help in recording FT-IR and DSC data.

\section{References}

[1] R. W. Munn and C. N. Ironside, Principles and Applications of Nonlinear Optical Materials, Chapman \& Hall, London, UK, 1993.

[2] S. P. Karna, "Electronic and nonlinear optical materials? The role of theory and modeling," Journal of Physical Chemistry A, vol. 104, no. 20, pp. 4671-4673, 2000.

[3] D. R. Kanis, M. A. Ratner, and T. S. Marks, "Design and construction of molecular assemblies with large second-order optical nonlinearities. Quantum chemical aspects," Chemical Reviews, vol. 94, no. 1, pp. 195-242, 1994.

[4] D. S. Chemla and J. Zyss, Non-Linear Optical Properties of Organic Molecular Crystals, vol. 1, Academic Press, London, UK, 1987. 
[5] D. J. Williams, "Organic polymeric and non-polymeric materials with large optical nonlinearities," Angewandte ChemieInternational Edition, vol. 23, no. 9, pp. 690-703, 1984.

[6] B. Ganapayya, A. Jayarama, R. Sankolli, V. R. Hathwar, and S. M. Dharmaprakash, "Synthesis, growth, and characterization of a new NLO material 3-(2,3-dimethoxyphenyl)-1-(pyridin-2yl)prop-2-en-1-one," Journal of Molecular Structure, vol. 1007, pp. 175-178, 2012.

[7] M. Albota, D. Beljonne, J. L. Brédas et al., "Design of organic molecules with large two-photon absorption cross sections," Science, vol. 281, no. 5383, pp. 1653-1656, 1998.

[8] T. Uchida, K. Kozawa, T. Sakai et al., "Novel organic SHG materials," Molecular Crystals and Liquid Crystals Science and Technology A, vol. 315, no. 1, pp. 135-140, 1998.

[9] J. Indira, P. P. Karat, and B. K. Sarojini, "Growth, characterization and nonlinear optical property of chalcone derivative," Journal of Crystal Growth, vol. 242, no. 1-2, pp. 209-214, 2002.

[10] B. Zhao, W. Q. Lu, Z. H. Zhou, and Y. Wu, "The important role of the bromo group in improvingthe properties of organic nonlinear optical materials," Journal of Materials Chemistry, vol. 10, pp. 1513-1517, 2000.

[11] G. J. Zhang, T. Kinoshita, K. Sasaki, Y. Goto, and M. Nakayama, "Second-harmonic generation of a new chalcone-type crystal," Applied Physics Letters, vol. 57, no. 3, article 221, 1990.

[12] A. N. Prabhu, A. Jayarama, V. Upadhyaya, and K. S. Bhat, "Synthesis, growth and characterization of $\pi$ conjugated organic nonlinear optical chalcone derivative," Materials Chemistry and Physics, vol. 138, no. 1, pp. 179-185, 2013.

[13] A. N. Prabhu, A. Jayarama, K. S. Bhat, and V. Upadhyaya, "Growth, characterization and structural investigation of a novel nonlinear optical crystal," Journal of Molecular Structure, vol. 1031, pp. 79-84, 2013.

[14] A. N. Prabhu, V. Upadhyaya, A. Jayarama, M. Srinivasulu, K. B. Manjunatha, and G. Umesh, "Synthesis, growth and characterization of 1-(5-chlorothiophen-2-yl)-3-(2,4, 5-trimethoxyphenyl) prop-2-en-1-one single crystal: a potential NLO material," in International Conference on Light Optics: Phenomena, Materials, Devices, and Characterization (OPTICS '11), AIP Conference Proceedings, pp. 538-540, Kerala, India, May 2011.

[15] A. N. Prabhu, A. Jayarama, R. Sankolli, T. N. G. Row, and V. Upadhyaya, "(2E)-1-(5-chloro-thio-phen-2-yl)-3-(2,3-dimethoxyphen-yl)prop-2-en-1-one," Acta Crystallographica E, vol. 67, no. 10, Article ID o2665, 2011.

[16] W. Kaminsky, "From CIF to virtual morphology using the WinXMorph program," Journal of Applied Crystallography, vol. 40, part 2, pp. 382-385, 2007.

[17] H. J. Ravindra, A. J. Kiran, S. R. Nooji et al., "Synthesis, crystal growth and characterization of a phase matchable nonlinear optical single crystal: p-chloro dibenzylideneacetone," Journal of Crystal Growth, vol. 310, no. 10, pp. 2543-2549, 2008.

[18] E. E. A. Shepherd, J. N. Sherwood, and G. S. Simpson, "The growth and perfection of organic non-linear optical crystals: $\mathrm{N}$ methyl urea (NMU) from methanol solution. III. The growth of large single crystals for optical examination," Journal of Crystal Growth, vol. 167, no. 3-4, pp. 709-715, 1996.

[19] S. K. Kurtz and T. T. Perry, "A powder technique for the evaluation of nonlinear optical," Journal of Applied Physics, vol. 39, no. 8, article 3728, 1968.

[20] R. A. Ganeev, A. I. Ryasnyanskii, M. K. Kodirov, S. R. Kamalov, and T. Usmanov, "Optical limiting in fullerenes, colloidal metal solutions, and semiconductors in the field of pico-and nanosecond pulses of an Nd:YAG laser," Optics and Spectroscopy, vol. 93, no. 5, pp. 789-796, 2002.

[21] M. Yin, H. P. Li, S. H. Tang, and W. Ji, "Determination of nonlinear absorption and refraction by single Z-scan method," Applied Physics B, vol. 70, no. 4, pp. 587-591, 2000. 

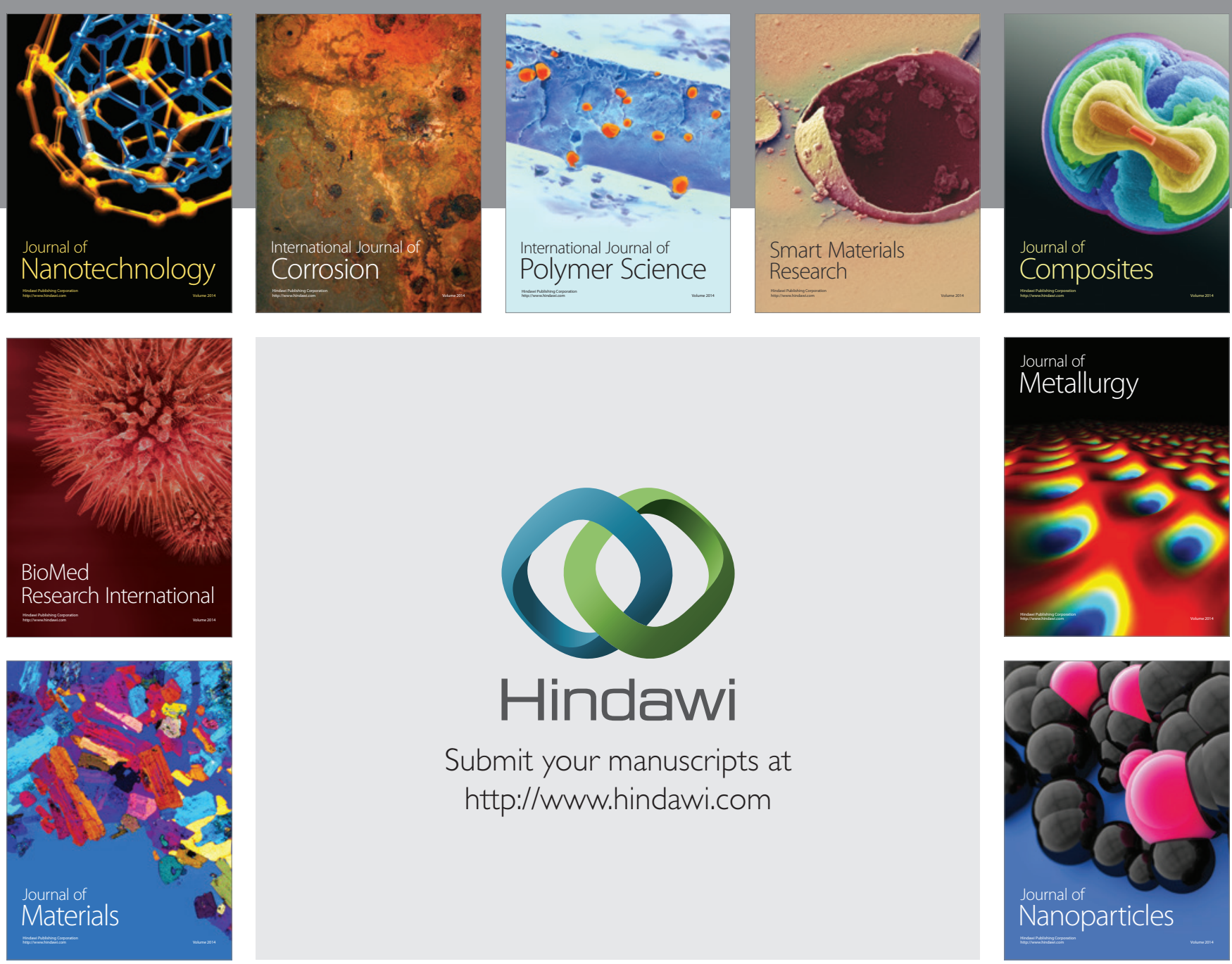

Submit your manuscripts at http://www.hindawi.com
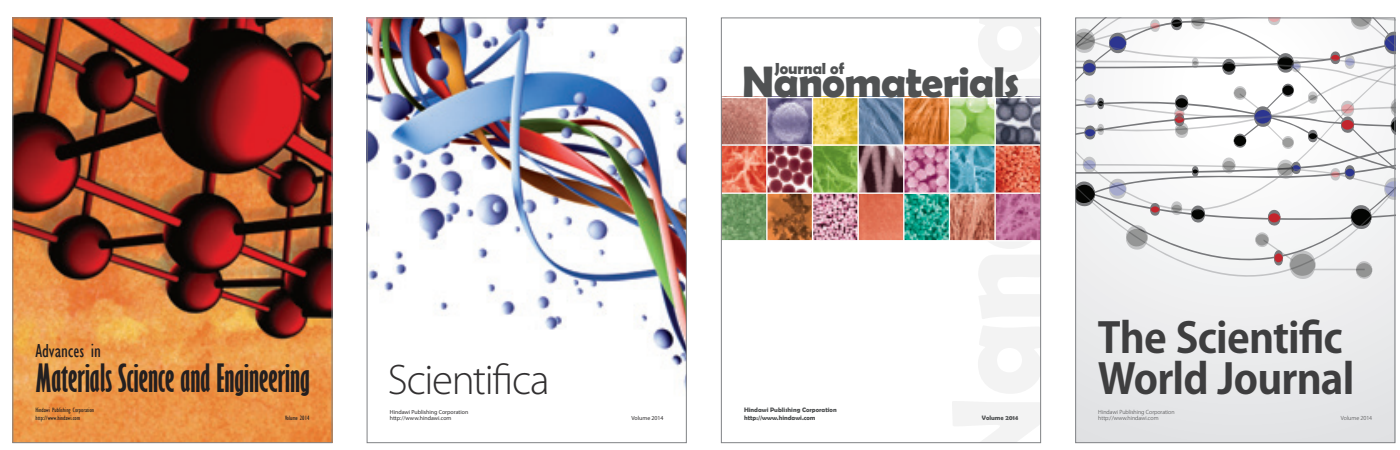

\section{The Scientific World Journal}
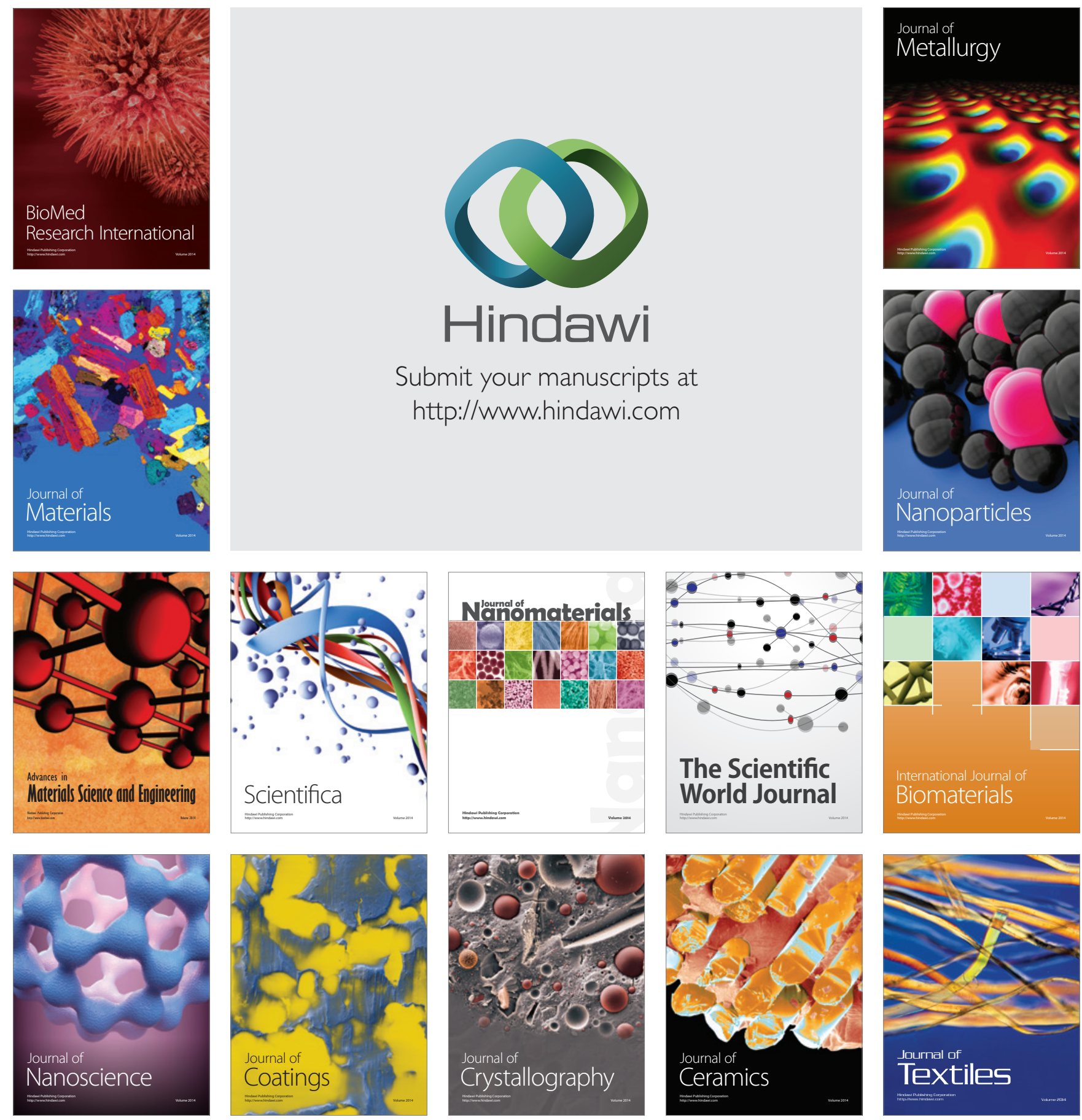